\title{
Staphylococcus aureus nasal carriage in rheumatoid arthritis: antibody response to toxic shock syndrome toxin-1
}

Department of Internal Medicine, University of Texas Southwestern Medical Center, 5323 Harry Hines Boulevard, Dallas, Texas, USA D Tabarya

W L Hoffman

Correspondence to: Dr Wayne Hoffman, Arthritis Consultation Center, Presbyterian Hospital, 8200 Walnut Hill Lane, Dallas, Texas 75231, USA.

\begin{abstract}
Objective-To determine the prevalence of Staphylococcus aureus nasal carriage and to compare antibody responses to two superantigens, staphylococcal toxic shock syndrome toxin-1 (TSST-1) and staphylococcal enterotoxin $A$ (SEA), in rheumatoid arthritis patients and normal subjects.

Methods -88 rheumatoid arthritis patients and 110 control subjects were cultured for nasal carriage of $S$ aureus; 62 isolates were bacteriophage typed. Twenty five patients and 11 spouses were tested for antibodies to TSST-1, SEA, and sonicate extracts of Bacteroides fragilis and Escherichia coli; 19 patients were HLA-DR typed.

Results-50\% of patients and $33 \%$ of normal subjects were $S$ aureus carriers. Bacteriophage typing of isolates suggested significant differences between strains isolated from the two groups. Patients showed higher IgG $(P=0.0025)$ and IgA $(P$ $=0.0372$ ) antibody levels to TSST-1 than normal spouses and these responses were not related to rheumatoid factor titres or HLA-DR type.

Conclusions-When compared to normals, rheumatoid arthritis patients more often carry $S$ aureus in their nasal vestibule, carry a distinct subpopulation of $S$ aureus strains, and have higher average antibody levels to TSST-1.
\end{abstract}

(Ann Rheum Dis 1996;55:822-828)

$S$ aureus secretes up to 30 different protein antigens, including at least eight $T$ cell superantigens ${ }^{1}$ : toxic shock syndrome toxin-1 (TSST-1) and staphylococcal enterotoxins A, $\mathrm{B}, \mathrm{C}_{1}, \mathrm{C}_{2}, \mathrm{C}_{3}, \mathrm{D}$, and $\mathrm{E}$. This makes $S$ aureus one of the principal sources of currently identified $T$ cell superantigens in the environment. $T$ cell superantigens have a dual affinity for major histocompatibility complex (MHC) class II molecules and for a relatively invariant region of the variable portion of the $\beta$ chain $(V \beta)$ of the $T$ cell antigen receptor to induce $T$ cell activation in a V $\beta$ restricted manner. ${ }^{1}$ Recent studies by Paliard et $a l^{2}$ have shown such T cell antigen receptor restriction-compatible with an intense stimulation by a microbial superantigen-in patients with rheumatoid arthritis. In addition, the demonstration of increased susceptibility to the development of rheumatoid arthritis in patients with selected genetic variants of the $\beta$ chain of the $T$ cell receptor ${ }^{3}$ also makes exploration of immune responses to $S$ aureus superantigens in rheumatoid arthritis of significant interest.

TSST-1 and staphylococcal enterotoxin A (SEA), which are commonly secreted $S$ aureus $\mathrm{T}$ cell superantigens, can also act as conventional antigens and elicit antibodies which may protect individuals from their toxic effects. Approximately $91 \%$ of healthy subjects have significant antibody titres to TSST-1, and $46 \%$ have significant antibody titres to SEA, ${ }^{4}$ even though only $38 \%$ of $S$ aureus strains can produce TSST- 1 and about $23 \%$ are potential producers of SEA. ${ }^{45}$

In addition to TSST-1, SEA, and the other T cell superantigens, $S$ aureus also produces protein A, which is a known B cell superantigen. ${ }^{6}$ Protein A stimulates utilisation of the $V_{H^{3}} 3$ heavy chain gene $^{6}$ and induces $\operatorname{IgM} R F$ production. . . Like TSST-1 and SEA, protein A can also act as a conventional antigen and has also been shown to induce an antibody response in $31 \%$ of rheumatoid arthritis patients. $^{8}$

Rheumatoid arthritis is an inflammatory arthritis of unknown aetiology, and many different infectious agents have been suggested as being involved in the pathogenesis of the disease. $S$ aureus is an attractive candidate because $33 \%$ of the normal population are nasal carriers of this ubiquitous organism ${ }^{10}$ and $S$ aureus secretes both $\mathrm{T}$ cell and $\mathrm{B}$ cell superantigens. To evaluate $S$ aureus as a possible causative agent in the pathogenesis of rheumatoid arthritis, we compared the antibody titres in rheumatoid arthritis patients and in normal spouses living in the same household to two commonly secreted $S$ aureus superantigens (TSST-1 and SEA) and to crude extracts of two common fecal flora, Escherichia coli and Bacteroides fragilis. We show that rheumatoid arthritis patients have an exaggerated antibody response to TSST-1, but share with spouse controls a similar antibody response to SEA and to the antigens of two other micro-organisms to which they are uniformly exposed.

\section{Methods}

PATIENTS AND CONTROL SUBJECTS

All the rheumatoid arthritis patients included in this study fulfilled the American College of Rheumatology criteria for the diagnosis of rheumatoid arthritis ${ }^{11}$ and were seen as outpatients in the Arthritis Consultation Center at Presbyterian Hospital of Dallas. Cultures from high in the anterior nares were performed in 88 
unselected rheumatoid arthritis patients (28 Caucasian men, 60 Caucasian women) with a mean age of 53.7 (SD 14.9) years (range 23 to 81 ) and a mean duration of disease of 8.8 (SD 7.4) years (range 0.3 to 35 ). Similar cultures were also taken from 110 unselected control subjects (62 Caucasian men, 48 Caucasian woman) with a mean age of 49.2 (SD 17.9) years (range 21 to 86 ). These 110 control subjects included non-laboratory hospital employees, friends of hospital workers, and household members of the rheumatoid arthritis patients. No clinical symptoms of local nasal infection were observed in any of the rheumatoid arthritis patients or control subjects.

Serum samples were obtained from 25 of the 88 rheumatoid arthritis patients at the time the nasal swabs were obtained. Many of the 25 patients (10 men, 15 woman) selected for further study had more severe, active rheumatoid arthritis than the total rheumatoid arthritis patient population as determined by physician global assessment. The mean age of the 25 patients was 53.3 (SD 12.5) years (range 24 to 79 ) and the mean duration of disease was 10.7 (SD 9.0) years (range 0.3 to 30 ). Nine (36\%) of the patients were being treated with disease modifying antirheumatic drugs (DMARD) and $11(44 \%)$ were treated with both DMARD and steroids. Serum samples were also obtained from 11 spouses (seven men, four woman) with a mean age of 61.9 (SD 8.8) years (range 45 to 74 ) of the 25 rheumatoid arthritis patients. Serum samples from spouses were chosen to control for environmental factors that could influence both exposure to and colonisation of $S$ aureus in the matched rheumatoid arthritis patient. Serum samples from rheumatoid arthritis patients and spouse controls were tested for antibody responses to TSST-1, SEA, and sonicate extracts of $E$ coli and $B$ fragilis.

\section{SERUM}

Clotted blood samples were separated and the serum adjusted to $0.02 \%$ (wt/vol) sodium azide before storage at $-20^{\circ} \mathrm{C}$. A $1 \mathrm{ml}$ aliquot of serum from each of 500 normal blood bank donors was pooled, treated with azide and stored at $-20^{\circ} \mathrm{C}$.

\section{CULTURE METHODS AND MEDIA}

To obtain the nasal culture, a moistened dual Rayon swab (Culturette, Marion Scientific Inc, Kansas City, MO, USA) was rotated high up in each anterior nostril, then streaked on sheep blood agar and mannitol salt agar plates (Difco, Detroit, MI, USA) which were incubated at $35^{\circ} \mathrm{C}$ for 48 hours. All gram positive cocci which were positive for both catalase and coagulase production were identified as $S$ aureus. The two control organisms, $B$ fragilis and $E$ coli, were isolated from stool cultures of a rheumatoid arthritis patient.

BACTERIOPHAGE TYPING

Each of 62 isolates of $S$ aureus ( 37 isolates from rheumatoid arthritis patients and 25 from controls) was classified by bacteriophage typing using the procedure of Blair and Williams. ${ }^{12} \mathrm{~A}$ set of 19 bacteriophage types, representative of four bacteriophage groups, was obtained from the American Type Culture Collection (Rockville, $\mathrm{MD}$, USA) and was used to generate a bacteriophage lysis profile for each $S$ aureus isolate. The following bacteriophage types were used to classify the isolates: group 1 (29, $52,52 \mathrm{~A}$, and 80$)$; group 2 (3A, $3 \mathrm{C}$, and 55$)$; group $3(6,42 \mathrm{E}, 47,53,54,75,77,83 \mathrm{~A}, 84$, and 85); and group 4 (42D and 81). Viability and specificity of each bacteriophage was confirmed by demonstrating that the host $S$ aureus strain (provided by the American Type Culture Collection) was lysed, while a non-host control strain of $S$ aureus was not lysed.

\section{ANTIGENS}

Extracts of $B$ fragilis and $E$ coli were obtained from cultures grown in thioglycolate and brain/ heart infusion broths (Difco, Detroit, MI, USA), respectively. $B$ fragilis was grown for 48 hours and $E$ coli was grown overnight, both at $35^{\circ} \mathrm{C}$. Cultures were centrifuged at $5000 \mathrm{~g}$ and washed three times with $0.1 \mathrm{M}$ phosphatebuffered saline (PBS). Each bacterial mass was sonicated for 35 minutes and then centrifuged at $5000 \mathrm{~g}$ for 20 minutes. The sediment was discarded, and the supernatant dialysed against $0.1 \mathrm{M}$ PBS for 24 hours at $4^{\circ} \mathrm{C}$, then filtered through a $0.2 \mu \mathrm{m}$ membrane (Nalgene, Nalge Co, Rochester, NY, USA). The turbidity of each extract was read at $600 \mathrm{~nm}$ on a spectrophotometer (Gilford Instrument Laboratories, Oberlin, OH, USA) to allow use of comparable amounts of each bacterial sonicate. TSST-1 and SEA were purchased from Toxin Technology Inc, Sarasota, FL, USA.

ELISA

Ninety six well microtitre plates (Immulon 1, Dynatech Laboratories, Chantilly, VA, USA) were coated with $115 \mu$ l of 0.15 M PBS (pH 7.4) containing $5 \mu \mathrm{g} \mathrm{ml}^{-1}$ of bovine serum albumin (BSA) (Sigma, St Louis, MO, USA), and $2 \mu \mathrm{g} \mathrm{m}^{-1}$ of either TSST-1 or SEA, and incubated at $4^{\circ} \mathrm{C}$ overnight. The next day the wells were aspirated and washed three times with $0.15 \mathrm{M}$ PBS. The unbound sites were blocked with $1 \%$ (wt/vol) BSA in PBS (BSA-PBS) for 2 hours at room temperature. After washing three times, $100 \mu \mathrm{l}$ of serum diluted 1:150 in BSA-PBS were added to each well, followed by incubation for 21 hours at room temperature. The wells were then washed for one hour with six changes and $100 \mu \mathrm{l}$ of horseradish peroxidase-conjugated $\mathrm{F}\left(\mathrm{ab}^{\prime}\right)_{2}$ fragments of rabbit antihuman IgG-Fc or IgA- $\alpha$-chain Jackson ImmunoResearch, West Grove, PA, USA) diluted 1:10 000 in BSA-PBS were added to each well. The plates were left at room temperature for one hour and washed again six times as above. Finally, $100 \mu \mathrm{l}$ of 3,3',5,5' tetra-methyl benzidine (Microwell Peroxidase Substrate, Kirkegaard and Perry Laboratories, Gaithersburg, MD, USA) were added to each well and the difference in absorbance at $450 \mathrm{~nm}$ and $630 \mathrm{~nm}$ was read after one hour using a Dynatech MR 700 Microplate Reader (Dynatech Laboratories 


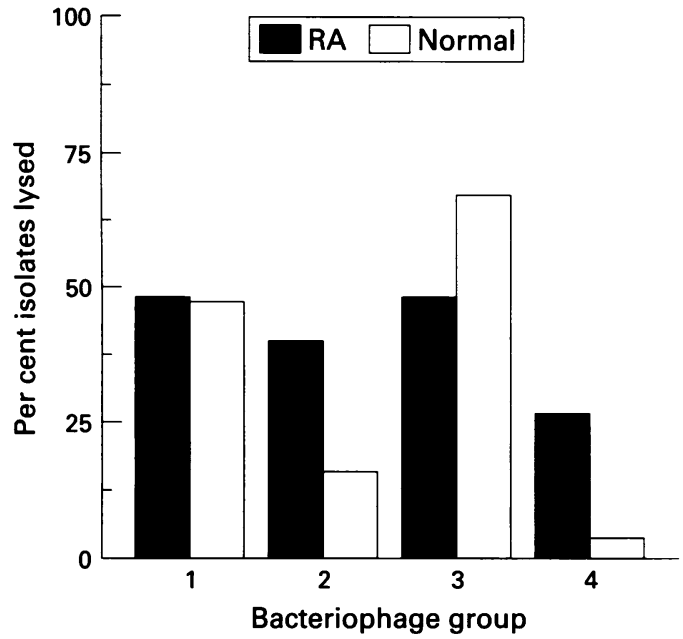

Figure 1 Percent $S$ aureus isolates from rheumatoid arthritis patients and normal subjects lysed by bacteriophages in groups 1,2, 3, and 4.

Inc, Chantilly, VA, USA). $B$ fragilis and $E$ coli bacterial extracts were diluted $1: 1500$ in 0.15 M PBS containing $5 \mu \mathrm{g} \mathrm{m}^{-1}$ BSA for coating the ELISA plates. The same procedure as described above was then followed except that the test sera were diluted 1:600 to test for IgG antibodies. Each serum and control was tested in duplicate and averaged, and then each experiment was repeated twice on different days to verify the results. Assay specificity was verified in each ELISA plate by replacing the antigen coat with BSA in one pair of wells and by replacing the test serum with BSA-PBS in a second pair of control wells.

For those sera with large amounts of antibody to TSST-1, it was occasionally necessary to make a greater dilution of the serum to allow optical density readings to fall on a standard curve between 0.5 and 1.0 optical density units. The results were then normalised to a dilution factor of $1: 150$, generating values as high as 7.316 optical density units.

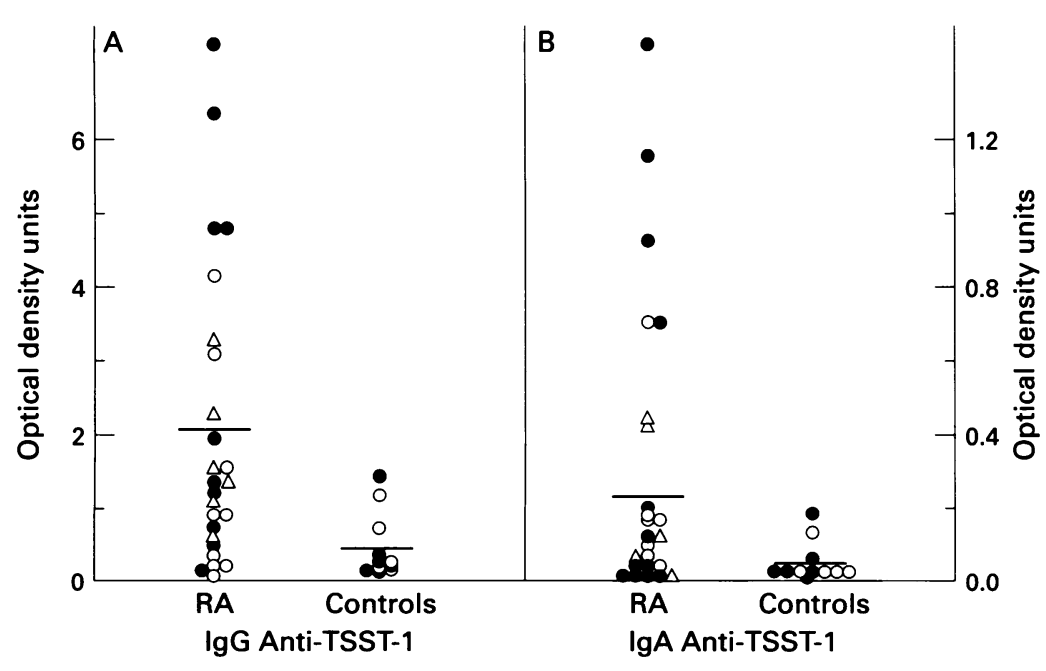

Figure 2 Comparison of antibody responses to TSST-1 between 25 rheumatoid arthritis patients and 11 spouses. Antibody levels are expressed as optical density units in the ELISA assay as described in Methods. (A) IgG values were determined using a serum dilution of $1: 150$ or were normalised to this dilution. (B) IgA values were determined using a serum dilution of 1:150. rheumatoid arthritis patients had significantly higher IgG $(P=0.0025)$ and $\operatorname{Ig} A(P=0.0372)$ antibody responses than spouses. Means are indicated by horizontal lines. $O$, carrier; $O$, non-carrier; $\triangle$, not cultured.
HLA-DR TYPING

Nineteen of the 25 rheumatoid arthritis patients studied for antibody responses were randomly selected and genetically typed for HLA-DRB1 alleles by the Tissue Transplantation Laboratory of the University of Texas Southwestern Medical Center at Dallas using allele-specific oligonucleotide probes to hybridise PCR amplified products. ${ }^{13}$

STATISTICAL METHODS

Data analysis was done by the Academic Computing Services at the University of Texas Southwestern Medical Center. Bacteriophage group lysis profiles were evaluated by a $\chi^{2}$ test. Antibody titres were compared using the nonparametric Wilcoxon test for unpaired samples. In both comparisons a $\mathrm{P}$ value of $<$ 0.05 was considered statistically significant. Data are presented as means (SD).

\section{Results}

STAPHYLOCCOCAL CARRIAGE AND BACTERIOPHAGE CLASSIFICATION

When 88 unselected rheumatoid arthritis patients were cultured, $44(50 \%)$ were found to harbour $S$ aureus in the anterior nares. The majority of these 88 patients were early rheumatoid arthritis patients who had received limited treatment and would not be expected to be immunosuppressed. When 110 unselected normal control subjects were similarly cultured, only $36(33 \%)$ were found to be $S$ aureus carriers. Thirty seven isolates from rheumatoid arthritis patients and 25 isolates from normal subjects were randomly selected and tested for similarities or differences using bacteriophage typing.

The bacteriophage typing patterns of the 62 $S$ aureus isolates from both groups indicated at least 49 different strains of $S$ aureus with nine non-typable strains. Even among the matched rheumatoid arthritis patients and their spouses who were both carriers, only one of the five pairs shared the same $S$ aureus strain, the isolates of which were lysed by bacteriophages 29, 53, 54, 75, and 83A. Three rheumatoid arthritis patients and no control subjects had an $S$ aureus strain which was only lysed by bacteriophage 29, and two other rheumatoid arthritis patients had a strain which was lysed only by bacteriophages $3 \mathrm{~A}, 3 \mathrm{C}$, and 55 . In all the other rheumatoid arthritis patients and non-rheumatoid arthritis control subjects $S$ aureus strains were cultured which appeared to be different, based on this bacteriophage typing. The number of isolates lysed by at least one bacteriophage in a group was counted and percent lysis is shown in fig 1 . When comparing the percentage of lysis in rheumatoid arthritis isolates with normal isolates, statistically significant differences were found with bacteriophage group $2(P=0.019)$ and group $4(\mathrm{P}=0.011)$. In overview, the $S$ aureus strains isolated from the anterior nares of rheumatoid arthritis patients were more likely to be lysed by bacteriophages in groups 2 and 4 than the $S$ aureus isolates from the control subjects (fig 1 ). 
Table 1 Comparison of antibody responses to TSST-1 and SEA between rheumatoid arthritis $(R A)$ patients and spouse controls

\begin{tabular}{|c|c|c|c|c|}
\hline \multirow[b]{2}{*}{ Serum source } & \multicolumn{2}{|l|}{ Anti-TSST-1 } & \multicolumn{2}{|l|}{ Anti-SEA } \\
\hline & $\overline{I g G}$ & $\operatorname{Ig} A$ & $\overline{I g G}$ & $\operatorname{Ig} A$ \\
\hline $\begin{array}{l}\text { RA patients }(n=25) \\
\text { Spouses }(n=11) \\
\text { Pool } 500 \text { normals } \\
P \text { (RA } v \text { spouses) }\end{array}$ & $\begin{array}{ll}2.098 & (2.015) \\
0.439 & (0.499) \\
0.630 & \\
0.0025 & \end{array}$ & $\begin{array}{ll}0.231 & (0.321) \\
0.042 & (0.060) \\
0.003 & \\
0.0372 & \end{array}$ & $\begin{array}{ll}0.078 & (0.061) \\
0.076 & (0.058) \\
0.047 & \\
\text { NS } & \end{array}$ & $\begin{array}{ll}0.021 & (0.026) \\
0.013 & (0.011) \\
0.003 & \\
\text { NS } & \end{array}$ \\
\hline
\end{tabular}

Mean antibody levels are expressed as optical density units (SD) in the ELISA assay as described in Methods. IgG values were determined using a serum dilution of 1:150 or were normalised to this dilution. IgA values were determined using a serum dilution of 1:150.

Table 2 Comparison of antibody responses to $B$ fragilis and $E$ coli sonicates between rheumatoid arthritis ( $R A)$ patients and spouse controls

\begin{tabular}{|c|c|c|c|c|}
\hline \multirow[b]{2}{*}{ Serum source } & \multicolumn{2}{|l|}{ Anti-B fragilis } & \multicolumn{2}{|l|}{ Anti-E coli } \\
\hline & $I g G$ & $\operatorname{Ig} A$ & $I g G$ & $\operatorname{Ig} A$ \\
\hline RA patients $(n=25)$ & $2.604(1.644)$ & $0.147(0.138)$ & $3.440(1.732)$ & $0.226(0.179)$ \\
\hline Spouses $(n=11)$ & $3.348(1.716)$ & $0.141 \quad(0.088)$ & $3.324(1.576)$ & $\begin{array}{l}0.149(0.100) \\
0.128\end{array}$ \\
\hline Pool 500 normals & 4.120 & 0.092 & 3.321 & 0.128 \\
\hline
\end{tabular}

Mean antibody levels are expressed as optical density units (SD) in the ELISA assay as described in Methods. IgG values were determined using a serum dilution of 1:600 while levels for IgA were determined using serum dilutions of $1: 150$. The values of IgG were then normalised to a dilution of $1: 150$ by multiplying by 4 .

IgG AND IgA ANTIBODIES TO TSST-1, SEA, AND TWO NON-S AUREUS BACTERIAL SONICATES

Twenty five rheumatoid arthritis patients were further tested for their antibody response to TSST-1, SEA, and two control antigen preparations from filtered sonicates of $B$ fragilis and $E$ coli. Rheumatoid arthritis patients showed an average of 4.7 times more IgG antibody ( $P=$ $0.0025)$ and 5.6 times more IgA antibody $(P=$ 0.0372 ) to TSST-1 than normal spouses. These results are presented in fig 2 and table 1 . When the antibody response in 11 of these 25 rheumatoid arthritis patients was compared with their matched spouses, 9 of 11 patients had higher IgG and IgA antibody responses to TSST-1 than their spouses.

Unlike the antibody titres to TSST-1, there were no significant differences in the average IgG or IgA antibody titres to SEA (table 1) or to the sonicates of $B$ fragilis and $E$ coli between rheumatoid arthritis patients and normal spouses (table 2). Some of the rheumatoid arthritis patients did show very low responses to the $B$ fragilis antigens when compared to spouse controls or pooled normal human sera, even though they had shown high responses to TSST-1. In both tables 1 and 2, the mean absorbance value of the pool of 500 normal sera was similar to the mean absorbance value of the spouse controls, showing that the average immune response in the sera of the

Table 3 Comparison of IgG and IgA antibody responses to TSST-1 and SEA between nasal $S$ aureus carriers and non-carriers

\begin{tabular}{|c|c|c|c|c|}
\hline \multirow[b]{2}{*}{ Serum source } & \multicolumn{2}{|l|}{ Anti-TSST-1 } & \multicolumn{2}{|l|}{ Anti-SEA } \\
\hline & $\operatorname{Ig} G$ & $\operatorname{Ig} A$ & $I g G$ & $\operatorname{Ig} A$ \\
\hline RA carriers $(n=10)$ & $2.989(2.625)$ & $0.335(0.433)$ & $0.084(0.056)$ & $0.027(0.035)$ \\
\hline $\begin{array}{l}\text { RA non-carriers } \\
(n=9)\end{array}$ & $1.335(1.459)$ & $0.146(0.222)$ & $0.074(0.073)$ & $0.023(0.020)$ \\
\hline Spouse carriers $(n=6)$ & $0.388(0.534)$ & $0.045(0.072)$ & $0.086(0.069)$ & $0.016(0.013)$ \\
\hline Spouse non-carriers & $0.502(0.508)$ & $0.038(0.049)$ & $0.064(0.045)$ & $0.010(0.006)$ \\
\hline
\end{tabular}

$(\mathrm{n}=5)$

Mean antibody levels are expressed as optical density units (SD) in the ELISA assay as described in Methods. IgG values were determined using a serum dilution of 1:150 or were normalised to this dilution. IgA values were determined using a serum dilution of 1:150. spouse controls was reflective of the immune response of the pool of 500 normal individuals.

The differences between the antibody responses to TSST-1 and SEA of rheumatoid arthritis $S$ aureus nasal carriers and non-carriers and of spouses who were carriers and non-carriers are presented in table 3 . Rheumatoid arthritis patients who were nasal carriers showed an average of 2.2 times as much anti-TSST-1 (both IgG and IgA) as the rheumatoid arthritis patients who were not carriers at the time of testing, but the differences in antibody concentrations between carrier and non-carrier patients were not significant. When spouse carriers and non-carriers were compared, there was no significant differences in either IgG or IgA anti-TSST-1 levels. There were also no significant differences in the antibody responses to SEA among the groups (table 3 ).

HLA DR TYPE AND IgG ANTIBODY RESPONSE TO TSST-1

A group of 19 of the rheumatoid arthritis patients from the above study were randomly selected and genetically typed for HLA-DRB1 by the Tissue Transplantation Laboratory at the University of Texas Southwestern Medical Center at Dallas. Twelve of the 19 patients $(63 \%)$ carried the HLA-DRB ${ }^{\star} 04$ allele. When the average IgG and IgA anti-TSST-1 antibody response in patients with the HLA-DRB $1{ }^{\star} 04$ allele was compared with the antibody response in patients lacking the HLA-DRB ${ }^{\star} 04$ allele to determine if the HLA-DRB $1{ }^{\star} 04$ allele influenced the antiTSST-1 response, no significant difference was noted.

\section{Discussion}

$S$ aureus may be cultured from asymptomatic normal subjects, not only from the nose (33\%), but also from the vagina $(4.6 \%),{ }^{14}{ }^{15}$ perineum $(22 \%),{ }^{16}$ and skin (12-20\%). ${ }^{9}$ The $33 \%$ nasal carriage rate of the 110 control subjects in this study corresponded well with previous studies. ${ }^{9}{ }^{10}$ Since nasal $S$ aureus carriers may show persistent or transient positivity, the 33\% carriage rate reflects the carrier status of the normal population at the time the nasal cultures were obtained. Transient positivity of nasal carriage and the possibility of carrying $S$ aureus undetected at other loci may help to explain why $91 \%$ of healthy subjects have significant antibody titres to TSST $-1,{ }^{5}$ even though only a third have detectable $S$ aureus in the anterior nares at any given time. ${ }^{910}$

A previous study of nasal carriage of $S$ aureus in non-rheumatoid arthritis patients ${ }^{10}$ showed an enrichment for patients who were HLA-DR3. Another study ${ }^{17}$ suggested that nasal carriage of $S$ aureus depends on the presence of a preferential binding site for the organism on the nasal epithelium, but that study did not show the site to be genetically determined. When 47 selected patients with toxic shock syndrome were studied they showed no identifiable HLA-A, B, C, or DR differences when compared to the known gene frequencies in a racially matched population. ${ }^{18}$ 
It is not known why rheumatoid arthritis patients have an increased nasal carriage rate of $S$ aureus, but our work confirms an unpublished 1972 study in which $50 \%$ of 48 rheumatoid arthritis patients and $27 \%$ of 48 controls (matched for age, sex, and race) carried $S$ aureus in their upper nasal vestibule (A McKusick, personal communication). In McKusick's study, which was completed before immunotherapy was used in the treatment of rheumatoid arthritis, no obvious differences in disease severity or type of treatment were associated with the carriage of $S$ aureus in the rheumatoid arthritis patients. Therefore, this 1972 study suggests that the treatment of rheumatoid arthritis patients with immunosuppressive drugs does not increase colonisation of the rheumatoid arthritis patients with $S$ aureus.

DNA fingerprinting ${ }^{19}$ or bacteriophage typing ${ }^{12}$ may be used to distinguish different strains of $S$ aureus. We used bacteriophage typing to examine the heterogeneity of $S$ aureus strains isolated in this study. ${ }^{12}$ Among the $62 S$ aureus isolates ( 37 rheumatoid arthritis and 25 normal isolates) that were studied by this method, at least 49 different strains were identified and nine strains were non-typable. The variability and complexity of the lysis profiles and the number of unique strains that were identified suggest that a potentially large number of different $S$ aureus strains exist. One interesting finding of the bacteriophage typing was the prevalence of lysis by group 2 and group 4 bacteriophages among the $S$ aureus strains isolated from rheumatoid arthritis patients (fig 1). Another interesting finding was that approximately $50 \%$ of the isolates obtained from both the rheumatoid arthritis patients and the normal controls were lysed by group 1 bacteriophages. Since group 1 bacteriophages have been associated with a higher frequency of TSST-1 production, the data suggest that both rheumatoid arthritis and normal controls were exposed to strains secreting TSST-1.

Superantigens have been implicated in the clonal expansion of selected $\mathrm{T}$ lymphocytes in toxic shock syndrome, ${ }^{20}$ rheumatoid arthritis, ${ }^{2}$ and Kawasaki disease. ${ }^{21}$ Since $S$ aureus represents one of the main sources of currently known superantigen exposure for humans, we compared the serological response of rheumatoid arthritis patients and their spouses to two common $S$ aureus superantigens, TSST- 1 and SEA, with the response to two non- $S$ aureus antigen mixtures from $B$ fragilis and $E$ coli. Figure 2 and table 1 show the substantial differences in the $\operatorname{IgG}$ and $\operatorname{IgA}$ antibody responses to TSST-1 between a group of the 25 rheumatoid arthritis patients and 11 of their spouses (controls for environmental factors that could influence both exposure to and colonisation of $S$ aureus in the matched rheumatoid arthritis patient). Some subjects in each group were nasal $S$ aureus carriers and some were not carriers. The demonstration of an average of 7.7-fold greater IgG anti-TSST-1 level in rheumatoid arthritis patients who were $S$ aureus carriers compared to the level in the spouse controls who also carried $S$ aureus is impressive (table 3), and suggests at least four possible explanations: (1) a much more intense immune response to TSST-1 in rheumatoid arthritis than non-rheumatoid arthritis subjects; (2) a much greater average antigen exposure in rheumatoid arthritis due to increased carriage rate; (3) $S$ aureus strain differences in rheumatoid arthritis compared to nonrheumatoid arthritis carriers resulting in either a greater synthesis rate of TSST-1 or variations in the amount of TSST-1 released into the nasal mucosa ${ }^{15}$; or (4) a response in rheumatoid arthritis patients to some micro-organism which shares antigen cross reactivity with TSST-1. For example, Ramesh et al ${ }^{22}$ identified a 20 amino acid peptide derived from TSST-1 which showed homology with the amino acid sequence 180-193 of the Mycobacterium tuberculosis heat shock protein $65 \mathrm{kDa}$ (HSP-65 kDa). This shared segment of HSP- $65 \mathrm{kDa}$ was recognised by $\mathrm{T}$ cells isolated from rats with $M$ tuberculosis induced adjuvant arthritis $^{23}$ and caused proliferation of peripheral blood mononuclear cells obtained from a majority of normal human donors. Increased immune responsiveness to the intact HSP-65 kDa protein has been shown in synovial fluid $T$ cells and in the serum antibody titres of rheumatoid arthritis patients, ${ }^{24-26}$ but it is not known whether the specific amino acid sequence shared with TSST-1 elicits a humoral response.

Our study also showed that normal control subjects, whether $S$ aureus carriers or not, have similar levels of both IgG and IgA anti-TSST-1 antibodies (table 3). This latter result is surprising but consistent with earlier studies in toxic shock syndrome in which healthy persons who were vaginal $S$ aureus carriers were compared to other healthy controls not carrying $S$ aureus, and found to have similar levels of anti-TSST-1 antibody. ${ }^{14}$

The selective enhancement of the IgG and IgA antibody response to TSST-1 in rheumatoid arthritis patients was not matched by their response to SEA (table 1) or to the antigen mixtures from $B$ fragilis or $E$ coli (table 2 ). The observation that rheumatoid arthritis patients only had a raised immune response to one of the four antigens tested and the other three titres were in the normal range suggests that the raised response to TSST-1 was not confounded by other factors, such as concomitant treatment, immunosuppression, a polyclonal immunoglobulin response, or rheumatoid factor. In fact, the increased IgG and IgA titres to TSST-1 in rheumatoid arthritis patients did not correlate with the IgM rheumatoid factor titres to heat aggregated IgG, and antibody titres to TSST-1 were unchanged after IgM rheumatoid factor was removed from the serum samples by gel filtration (data not shown). A recent study that compared the serum IgM titres to staphylococcal enterotoxin B (SEB) in rheumatoid arthritis patients and normal controls also found no correlation between the increased titres of antibodies to SEB in rheumatoid arthritis patients and rheumatoid factor titres. ${ }^{27}$ 
In conclusion, although it is not known why some rheumatoid arthritis patients have dramatically increased antibody titres to TSST-1, $S$ aureus remains an interesting organism to be considered as a causative agent in rheumatoid arthritis pathogenesis for several reasons. For example, TSST-1 has been shown to be arthritogenic in mice ${ }^{28}$; in addition, $S$ aureus is ubiquitous and may be carried by humans at various sites either persistently or transiently; it makes up to 30 different protein antigens, including both $T$ cell and $B$ cell superantigens, and protein $A$ can induce both IgM rheumatoid factor production and polyclonal B cell activation. The complexity of the bacteriophage lysis profiles suggests that a large number of $S$ aureus strains exists and rheumatoid patients appear to carry a distinct subpopulation of $S$ aureus strain in their nasal vestibule. If $S$ aureus was involved in the pathogenesis of rheumatoid arthritis, the potentially large number of unique strains, the possibility of variations in the synthetic profile of each strain, and the significant differences in the immune response patterns of individuals to specific antigens could explain why approximately one third of the population are $S$ aureus carriers but do not have rheumatoid arthritis. Additional studies are needed to determine why rheumatoid arthritis patients carry a unique population of $S$ aureus stains and have increased antibody titres to TSST-1.

We thank Drs J Donald Smiley, Sterling E Moore Jr, and Max Grow for obtaining the nasal cultures and blood samples from patients with rheumatoid arthritis and their spouses, and for suggestions in the preparation of this manuscript. We thank Ann $O$ Ruggles for technical assistance. We also thank Drs Peter Stastny and Marcelo Fernandez-Vina of the Tissue Transplantation Laboratory of the University of Texas Southwestern Medical Center at Dallas for the HIA-DRB1 typing of 19 rheumatoid arthritis patients. This work has been supported by the supported by Jackson Foundation and the Hawn Foundation.

1 Marrack P, Kappler J. The staphylococcal enterotoxins and their relatives. Science 1990;248:705-11.

2 Paliard X, West SG, Lafferty JA, Clements JR, Kappler JW, Marrack P, et al. Evidence for the effects of a superantigen Marrack P, et al. Evidence for the effects of a supera
in rheumatoid arthritis. Science 1991;253:325-9.

3 McDermott M, Kastner DL, Holloman JD, Schmidt-Wolf G, Lundberg AS, Sinha AA, et al. The role of T cell receptor $\mathrm{b}$ chain genes in susceptibility to rheumatoid arthritis. Arthritis Rheum 1995;38:91-5.

4 Notermans S, Van Leeuwen WJ, Dufrenne J, Tips PD. Serum antibodies to enterotoxins produced by Staphylococcus aureus with special reference to enterotoxin $F$ and toxic shock syndrome. $₹$ Clin Microbiol 1983;18:1055-60.

5 Ritz HL, Kirkland J, Bond GG, Warner EK, Petty GP. Association of high levels of serum antibody to staphylocoAssociation of high levels of serum antibody to staphylococcal toxic shock antigen with nasal carriage of toxic shock antigen producing strain

6 Sasano M, Burton DR, Silverman GJ. Molecular selection of human antibodies with an unconventional bacterial B cell antigen. $\mathcal{f}$ Immunol 1993;151:5822-37.
7 Levinson AI, Wheatley ZYL, Kozlowski L, Zom S. IgM heumatoid factor produced in response to $S$. auren cowan I: Role of protein A and preferential utilization of $\mathrm{V}_{\mathrm{H}} 3$ heavy chains [abstr]. FASEB F 1993; 7:A1551.

8 Takeuchi T, Hosono O, Koide J, Amano K, Sekine H, Abe $\mathrm{T}$. The presence of anti-protein $\mathrm{A}$ antibodies in patients with theumatoid arthritis. Scand 7 Immunol 1991;33:585 92.

9 Williams REO. Healthy carriage of Staphylococcus aureus: its prevalence and importance. Bacteriol Rev 1963;27:56-71.

10 Kinsman OS, McKenna R, Noble WC. Association between histocompatibility antigens (HLA) and nasal carriage of Staphylococcus aureus. F Med Microbiol 1983;16:215-20.

11 Arnett FC, Edworthy SM, Bloch DA, McShane DJ, Fries JF, Cooper NS, et al. The American Rheumatism Association 1987 revised criteria for the classification of rheumatoid arthritis. Arthritis Rheum 1988;31:315-24.

12 Blair JE, Williams REO. Phage typing of staphylococci. Bull WHO 1961;24:771-84.

13 Fernandez-Vina MA, Falco M, Gao X, Cerna M, Sun Y, Raimondi E, et al. DQA1 ${ }^{\star} 03$ subtypes have different associations with DRB1 and DQB1 alleles. Hum Immunol 1994;39:290-8.

14 Bonventre PF, Linnemann C, Weckbach LS, Staneck JL, Buncher CR, Vigdorth E, et al. Antibody responses to toxic-shock-syndrome (TSS) toxin by patients with TSS and by healthy staphylococcal carriers. $\mathcal{F}$ Infect Dis and by healthy

15 Mittag H-C. Toxic shock syndrome and the other staphylococcal toxicoses. Stuttgart:: Schattauer, 1988.

16 Ridley M. Perineal carriage of Staph aureus. BMf 1959; i:270-3.

17 Aly R, Shinefield HI, Strauss WG, Maibach HI. Bacterial adherence to nasal mucosal cells. Infect Immun 1977; 17:546-9.

18 Latham RH, Haslam BT, Dewitt C, Skolnick M, Smith CB. Histocompatibility leukocyte antigens in patients with toxic-shock syndrome [letter]. $\mathcal{F}$ Infect Dis 1983;147:783.

19 Ichiyama S, Ohta M, Shimokata K, Kato N, Takeuchi J. Genomic DNA fingerprinting by pulsed-field gel electrophoresis as an epidemiological marker for study of nosocomial infections caused by methicillin-resistant Staphylococcus aureus. F Clin Microbiol 1991;29:2690-5.

20 Choi Y, Lafferty JA, Clements JR, Todd JK, Gelfand EW, Kappler J, et al. Selective expansion of T cells expressing V beta 2 in toxic shock syndrome. $f$ Exp Med 1990;172:9814.

21 Abe J, Kotzin BL, Jujo K, Melish ME, Glode MP, Kohsaka $\mathrm{T}$, et al. Selective expansion of $\mathrm{T}$ cells expressing T-cell receptor variable region $V$ beta 2 and $V$ beta 8 in Kawasaki disease. Proc Natl Acad Sci USA 1992;89:4066-70.

22 Ramesh N, Parronchi P, Ahern D, Romagnani S, Geha R. A toxic shock syndrome toxin-1 peptide that shows homology to amino acids 180-193 of mycobacterial heat shock protein 65 is presented as conventional antigen. Immunol protein 65 is presented

23 van Eden W, Thole JER, van der Zee R, Noordzij A, van Embden JDA, Hensen EJ, et al. Cloning of the mycobacterial epitope recognized by $T$ lymphocytes in adjuvant arthritis. Nature 1988;331:171-3.

24 Cells L, Vandevyver C, Geusens P, Dequeker J, Raus J, Zhang J. Evidence for clonal restriction of heat shock protein specific synovial fluid $T$ cells in rheumatoid arthritis [abstr]. Arthritis Rheum 1994;37:S312. .

25 Bahr GM, Rook GAW, Al-Saffar M, van Embden J, Stanford IL, Behbehani K. Antibody levels to mycobacteStanford J, Behbehani K. Antibody levels to mycobactehigh levels of antibody to the $65 \mathrm{kDa}$ heat shock protein of high levels of antibody to the $65 \mathrm{kDa}$ heat shock protein of
$M$. bovis in rheumatoid arthritis. Clin Exp Immunol M. bovis in the
$1988 ; 74: 211-5$.

26 Tsoulfa G, Rook GAW, Bahr GM, Sattar MA, Behbehani K, Young DB, et al. Elevated IgG antibody levels to the mycobacterial $65-\mathrm{kDa}$ heat shock protein are characteristic of patients with rheumatoid arthritis. Scand f Immunol 1989; 30:519-27.

27 Origuchi T, Eguchi K, Kawabe Y, Yamashita I, Mizokami A, Ida $H$, Nagataki $S$. Increased levels of serum IgM antibody Ida $\mathrm{H}$, Nagataki $S$. Increased levels of serum IgM antibody to staphylococcal enterotoxin B in patients with

28 Abdelnour A, Bremell T, Tarkowski A. Toxic shock syndrome toxin 1 contributes to the arthritogenicity of Staphylococcus aureus. F Infect Dis 1994;170:94-99. 